\title{
EPR Study of Ammonium Nitrate Doped with Copper(II) Ions
}

\author{
W. Wojtowicz And A.B. WiȨCKOWski \\ Institute of Physics, University of Zielona Góra \\ Prof. Z. Szafrana 4a, 65-516 Zielona Góra, Poland
}

\begin{abstract}
This work is devoted to a study of the structural changes in a single crystal of ammonium nitrate, $\mathrm{NH}_{4} \mathrm{NO}_{3}$, doped with copper(II) cations by electron paramagnetic resonance. Ammonium nitrate crystallizes at atmospheric pressure in several polymorphic forms, phase VII $\rightarrow \mathrm{V} \rightarrow \mathrm{IV} \rightarrow$ $\mathrm{III} \rightarrow \mathrm{II} \rightarrow \mathrm{I} \rightarrow$ melt, with transition temperatures of $103 \mathrm{~K}, 255 \mathrm{~K}, 305 \mathrm{~K}$, $357 \mathrm{~K}, 398 \mathrm{~K}$, and $443 \mathrm{~K}$, respectively. The aim of our work was to study the temperature phase transition $\mathrm{V} \rightarrow \mathrm{IV}$ at about $255 \mathrm{~K}$ using electron paramagnetic resonance technique. The electron paramagnetic resonance spectra were performed using an X-band spectrometer with microwave frequency of $9.4 \mathrm{GHz}$ and magnetic modulation of $100 \mathrm{kHz}$ in the temperature range of 153-296 K. For a single crystal the angular dependence of the copper(II) electron paramagnetic resonance spectra was measured at $293 \mathrm{~K}$ and $168 \mathrm{~K}$. The anisotropic behaviour measured at $293 \mathrm{~K}$ points to the existence of one kind of two equivalent copper(II) complexes with inverse $\boldsymbol{g}$ and $\boldsymbol{A}$ tensors. A second pair of equivalent complexes also with inverse $\boldsymbol{g}$ and $\boldsymbol{A}$ tensors was observed. The minimal values of $g$-factors correspond to the maximum values of $A$. The angular dependence taken at $168 \mathrm{~K}$ shows the existence of two types of non-equivalent copper complexes which differ in comparison with the complexes observed at room temperature. The temperature dependence of the intensities of hyperfine structure lines for all copper(II) complexes observed shows a phase transition $\mathrm{V} \rightarrow \mathrm{IV}$ occurring in the temperature range of 237-246 K with a hysteresis. One of the hyperfine structure lines of a copper(II) complex measured at low temperatures shows a superhyperfine structure with line intensities 1:2:3:2:1 originating from the interaction of the copper ${ }^{63,65} \mathrm{Cu}(I=3 / 2)$ nucleus with two ${ }^{14} \mathrm{~N}(I=1)$ nuclei of two ammonia, $\mathrm{NH}_{3}$, ligand molecules.
\end{abstract}

PACS numbers: $61.50 . \mathrm{Ks}, 76.30 . \mathrm{Fc}$ 


\section{Introduction}

Ammonium nitrate, $\mathrm{NH}_{4} \mathrm{NO}_{3}$, is used as a component of blasting-powders and as a nitrogen fertilizer. Ammonium nitrate is also interesting in investigations of the dynamics and the mechanism of phase transitions in crystals.

Ammonium nitrate, $\mathrm{NH}_{4} \mathrm{NO}_{3}$, crystallises at atmospheric pressure in six polymorphic forms, phase VII $\rightarrow \mathrm{V} \rightarrow \mathrm{IV} \rightarrow \mathrm{III} \rightarrow \mathrm{II} \rightarrow \mathrm{I} \rightarrow$ melt, with transition temperatures of $103 \mathrm{~K}, 255 \mathrm{~K}, 305 \mathrm{~K}, 357 \mathrm{~K}, 398 \mathrm{~K}$, and $443 \mathrm{~K}$, respectively [1, 2]. The room-temperature phase (IV) is orthorhombic, belonging to the space group Pmmn $\left(D_{2 h}^{13}\right)$ with two $\mathrm{NH}_{4} \mathrm{NO}_{3}$ formula units per unit cell. The low temperature phase $(\mathrm{V})$ is orthorhombic and belongs to the space group Pccn $\left(D_{2 h}^{13}\right)$ with eight $\mathrm{NH}_{4} \mathrm{NO}_{3}$ formula units per unit cell. (Earlier structural study of the phase $\mathrm{V}$ showed that it has a tetragonal symmetry $\mathrm{P}_{2}\left(C_{4}^{3}\right)$ but new results suggest rather the orthorhombic symmetry [2].) A view of the structure of ammonium nitrate in phase IV was presented by Choi, Mapes, and Prince [1].

After doping the crystal with cations, the temperature of the phase transition $\mathrm{V} \rightarrow \mathrm{IV}$ is shifted to lower temperatures. The aim of our work was to study the temperature phase transition $\mathrm{V} \rightarrow \mathrm{IV}$ at about $255 \mathrm{~K}$ using EPR technique in a single crystal of ammonium nitrate doped with copper(II) cations.

In our earlier EPR study we have investigated copper $\mathrm{Cu}^{2+}$ cations in triglycine sulphate TGS, $\left({ }^{+} \mathrm{NH}_{3} \mathrm{CH}_{2} \mathrm{COO}^{-}\right)\left({ }^{+} \mathrm{NH}_{3} \mathrm{CH}_{2} \mathrm{COOH}\right)_{2} \mathrm{SO}_{4}^{2-}$, faujasite and triammonium hydrogen disulphate, $\left(\mathrm{NH}_{4}\right)_{3} \mathrm{H}\left(\mathrm{SO}_{4}\right)_{2}$ [3]. In the literature we have not found any results on EPR study of ammonium nitrate, $\mathrm{NH}_{4} \mathrm{NO}_{3}$, doped with copper(II) cations. Only EPR studies of the phase transitions $\mathrm{V} \rightarrow \mathrm{IV} \rightarrow$ $\mathrm{III} \rightarrow \mathrm{II}$ in melts of ammonium nitrate and copper(II) oxide, $\mathrm{CuO}$ [4], and of irradiated samples of ammonium nitrate [5], have been published. Preliminary results of our study were presented previously [3].

\section{Experimental}

Single crystals of ammonium nitrate, $\mathrm{NH}_{4} \mathrm{NO}_{3}$, were obtained at room temperature by slow evaporation of a saturated aqueous solution of ammonium nitrate, where $1 \%$ copper(II) nitrate, $\mathrm{Cu}\left(\mathrm{NO}_{3}\right)_{2}$, was added. The concentration of copper(II) ions in the crystal is of one order of magnitude smaller. Investigated crystals of ammonium nitrate have the form of prisms elongated along the $a$-axis with different dimensions, e.g. $20 \times 3 \times 1 \mathrm{~mm}$.

The EPR spectra were performed using an X-band spectrometer (made by RADIOPAN, Poznań) with the microwave frequency of $9.4 \mathrm{GHz}$ and the magnetic modulation of $100 \mathrm{kHz}$ in the temperature range of $153-296 \mathrm{~K}$. The temperature was controlled by passing liquid nitrogen vapours through a quartz dewar with the sample positioned in the microwave cavity and measured with a copper-constantan thermocouple with $\pm 1 \mathrm{~K}$ accuracy. The EPR spectra were found to be anisotropic. For a single crystal the angular dependence of the copper(II) EPR spectra was measured at $293 \mathrm{~K}$ and $168 \mathrm{~K}$. 


\section{Results and discussion}

\subsection{Anisotropy of EPR spectra}

As an example, two typical EPR spectra in the directions of the crystallographical axes $b$ and $c$ of a sample of copper(II) doped monocrystal of ammonium nitrate measured at room temperature $(293 \mathrm{~K})$ are shown in Fig. 1a and b. In Fig. 2 we present the angular dependence (anisotropy) of the EPR spectrum in the $b-c$ plane, which is perpendicular to the $a$ axis being parallel to the length of the prism. Two kinds of structurally non-equivalent copper(II) complexes, denoted as $\mathrm{Cu}^{2+}(\mathrm{A})$ and $\mathrm{Cu}^{2+}(\mathrm{B})$, are observed. The integral intensity of the $\mathrm{Cu}^{2+}(\mathrm{B})$ line is of about one order of magnitude smaller than the one of the $\mathrm{Cu}^{2+}(\mathrm{A})$ line. Each kind of complexes exists twice as two magnetically equivalent centres, we denote
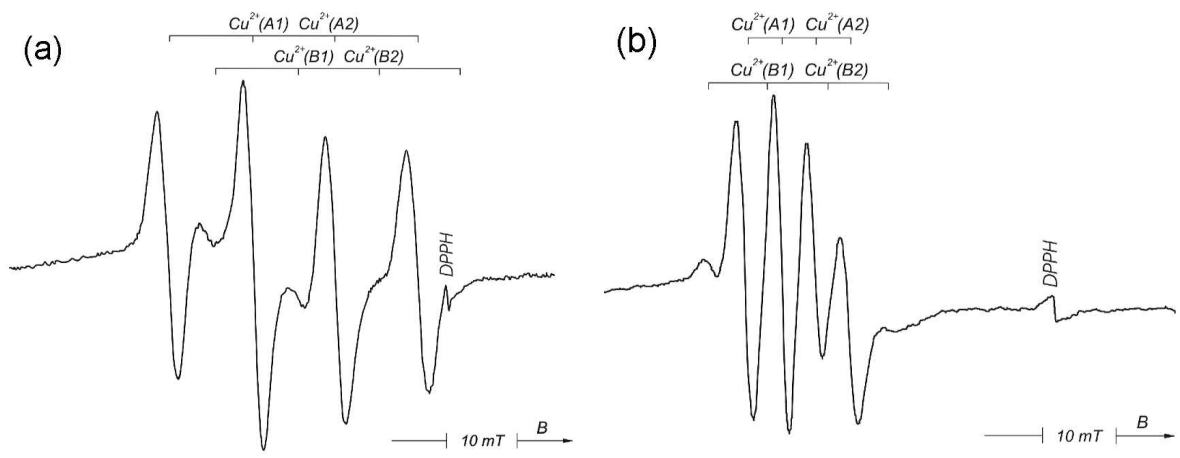

Fig. 1. EPR spectrum of copper(II) complexes in ammonium nitrate at room temperature. External magnetic field $\boldsymbol{B}$ is parallel to the $b(\mathrm{a})$ and $c$ (b) axis of the crystal.

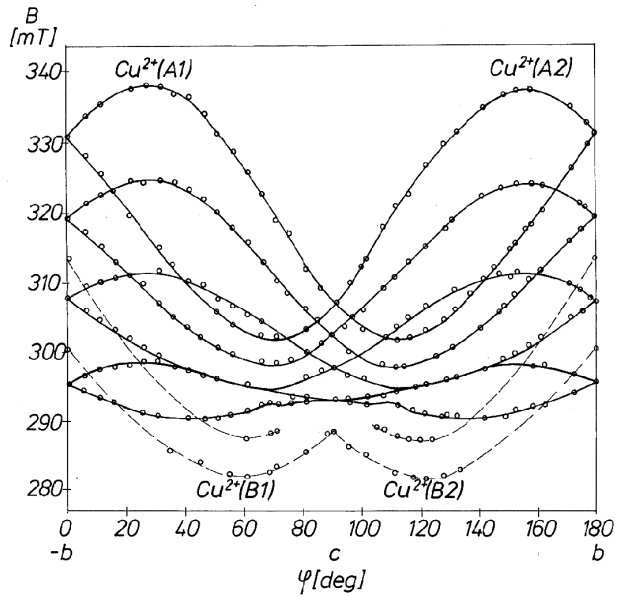

Fig. 2. Angular dependence of hyperfine structure lines of copper(II) complexes in ammonium nitrate in the $b-c$ plane. 
them as $\mathrm{Cu}^{2+}(\mathrm{A} 1), \mathrm{Cu}^{2+}(\mathrm{A} 2), \mathrm{Cu}^{2+}(\mathrm{B} 1)$, and $\mathrm{Cu}^{2+}(\mathrm{B} 2)$. The EPR spectrum of each complex consists of four nearly equidistant hyperfine structure (hfs) lines resulting from interactions of the electron spin $S=1 / 2$ of the $\mathrm{Cu}^{2+}$ cation with the nuclear spin $I=3 / 2$ for one of the both ${ }^{63,65} \mathrm{Cu}$ isotope nuclei. The splitting of the outer component hfs lines (for $m_{I}=-3 / 2 \rightarrow-3 / 2$ and $+3 / 2 \rightarrow+3 / 2$ transitions) caused by the ${ }^{63,65} \mathrm{Cu}$ isotope effect was not visible. Quadrupole effects were not observed. The values of the linewidth $\Delta B_{\mathrm{pp}}$ of the individual component hfs lines for the $\mathrm{Cu}^{2+}(\mathrm{A})$ and $\mathrm{Cu}^{2+}(\mathrm{B})$ complexes amounted to approximately 2.02 and $2.26 \mathrm{mT}$, respectively.

The spin Hamiltonian for the copper(II) cation in the case being under investigation can be written in the following form:

$$
H=\beta \boldsymbol{B} \cdot \boldsymbol{g} \cdot \boldsymbol{S}+\boldsymbol{I} \cdot \boldsymbol{A} \cdot \boldsymbol{S} .
$$

From the angular dependence of the EPR spectrum for the $\mathrm{Cu}^{2+}(\mathrm{A})$ complex in the planes $a-b, b-c$, and $c-a$, the principal values of the $\boldsymbol{g}$ and $\boldsymbol{A}$ tensors were measured: $g_{z}=2.037, g_{y}=2.197, g_{x}=2.267, A_{z}=16.59 \mathrm{mT}, A_{y}=6.06 \mathrm{mT}$, $A_{x}=4.1 \mathrm{mT}$. The principal axes of the $\boldsymbol{g}$ and $\boldsymbol{A}$ tensors coincide.

The anisotropic behaviour of the pair of $\mathrm{Cu}^{2+}(\mathrm{A})$ complexes measured at $293 \mathrm{~K}$ points to the existence of one kind of two magnetically equivalent centres with inverse $g$ and $A$ factors: $g_{z}<g_{y}<g_{x}, A_{z}>A_{y}>A_{x}$. The minimal value of $g$-factor corresponds to the maximum value of $A$. After assuming the rhombic symmetry $\left(D_{2 h}, D_{2}, C_{2 \nu}\right)$ for the crystal field, the ground state of the copper(II) cation, where the orbitals $\left|x^{2}-y^{2}\right\rangle$ and $\left|z^{2}\right\rangle$ are mixed, is given by the following wave function:

$$
|0\rangle=a\left|x^{2}-y^{2}\right\rangle+b\left|z^{2}\right\rangle, \quad a^{2}+b^{2}=1 .
$$

It follows from an analysis of the principal $g$ tensor values given above for the $\mathrm{Cu}^{2+}(\mathrm{A})$ complex that the state $\left|z^{2}\right\rangle$ is dominant, and we have estimated the corresponding values $a=0.28$ and $b=0.96$ approximately. The case when the state $\left|z^{2}\right\rangle$ is dominant, leads to the conclusion that the $\mathrm{Cu}^{2+}(\mathrm{A})$ complex possesses the symmetry of a distorted trigonal bipyramid. A similar case was presented by Hoffmann [6] for copper $\mathrm{Cu}^{2+}$-doped ammonium sulphate, $\left(\mathrm{NH}_{4}\right)_{2} \mathrm{SO}_{4}$.

The second pair of the $\mathrm{Cu}^{2+}(\mathrm{B})$ complexes has also inverse $g$ and $A$ factors. Since the resonance lines of the type $\mathrm{Cu}^{2+}$ (B) complex have very small integral intensities, this complex will not be considered here.

\subsection{Temperature dependence of EPR spectra}

In our study the attention was drawn to the temperature phase transition $\mathrm{V}$ $\rightarrow$ IV occurring for a pure crystal of ammonium nitrate at about $255 \mathrm{~K}$. It is well known that doping the ammonium nitrate crystal with paramagnetic cations, the $\mathrm{V} \rightarrow \mathrm{IV}$ phase transition temperature is decreased [7]. In Fig. 3 some EPR spectra obtained during decreasing the temperature from $296 \mathrm{~K}$ to $153 \mathrm{~K}$ are shown. The EPR spectra shown in Fig. 4 were obtained during cooling and heating the sample. 


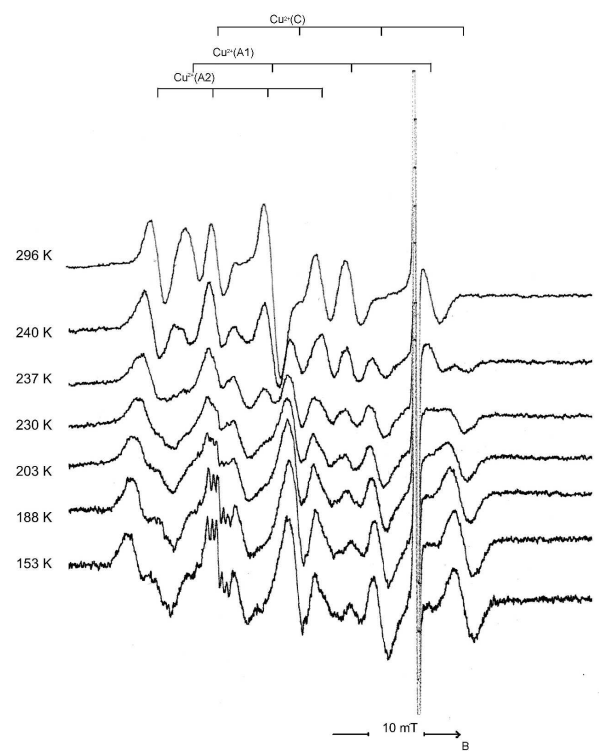

Fig. 3. Changes with temperature (cooling) of EPR spectra of copper(II) complexes in ammonium nitrate. External magnetic field forms the angle $\varphi=21^{\circ}$ with the $b$ axis in the $b-c$ plane.

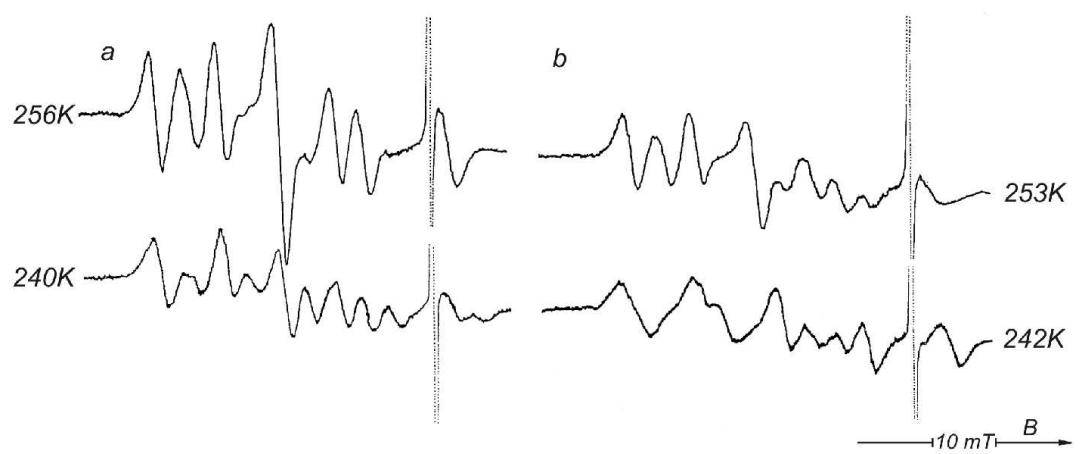

Fig. 4. Changes with temperature ( $\mathrm{a}$ - cooling, $\mathrm{b}$ - heating) of EPR spectra of copper(II) complexes in ammonium nitrate. External magnetic field forms the angle $\varphi=21^{\circ}$ with the $b$ axis in the $b-c$ plane. The differences of the spectra at similar temperatures points to the existence of hysteresis phenomenon.

Figures 3 and 4 point to a decrease in the phase transition temperature below $246 \mathrm{~K}$ and an occurrence of a thermal hysteresis of the phase transition. While decreasing the temperature, a diminishing of the amplitude of the component hfs lines can be seen. Simultaneously, new component hfs lines are appearing. A diminishing of the Raman spectra, when bringing closer to the $\mathrm{V} \rightarrow \mathrm{IV}$ phase transition temperature, was also seen by other authors [8]. The decrease of one kind of complexes and 
the increase of the other type of complexes with changing temperature can be explained by assuming a change of coordinative symmetry of $\mathrm{Cu}^{2+}$ cations near the phase transition point, leading to a significant line broadening and making the spectra impossible to be recorded.

The angular dependence taken at $168 \mathrm{~K}$ shows the existence of two types of non-equivalent copper(II) complexes denoted as $\mathrm{Cu}^{2+}(\mathrm{C})$ and $\mathrm{Cu}^{2+}(\mathrm{D})$, which differ in comparison with complexes $\mathrm{Cu}^{2+}(\mathrm{A})$ and $\mathrm{Cu}^{2+}(\mathrm{B})$ observed at room temperature. For $\mathrm{Cu}^{2+}(\mathrm{C})$ and $\mathrm{Cu}^{2+}(\mathrm{D})$ complexes we also observed inverse $\boldsymbol{g}$ and $\boldsymbol{A}$ tensors. The $\mathrm{Cu}^{2+}(\mathrm{C})$ complex is a distorted form of the $\mathrm{Cu}^{2+}(\mathrm{A})$ complex.

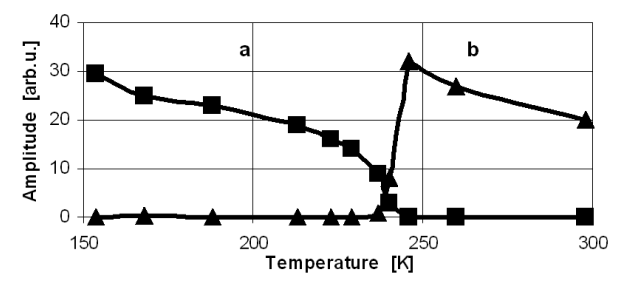

Fig. 5. Temperature dependence of the amplitude of selected individual hfs lines for copper(II) complexes in ammonium nitrate: a - fourth hfs line of $\mathrm{Cu}^{2+}(\mathrm{C})$ complex, $\mathrm{b}$ - first hfs line of $\mathrm{Cu}^{2+}(\mathrm{A} 1)$ complex. With the aim to obtain a clear picture, the other hfs lines are omitted, but the run of appropriate curves is similar.

The temperature dependence of the amplitudes of component hfs lines for all copper(II) complexes observed, shows a phase transition V $\rightarrow$ IV occurring in the temperature range of 237-246 K. Two examples of this dependence are shown in Fig. 5.

\subsection{Superhyperfine structure}

One of the hfs lines (for the transition $3 / 2 \rightarrow 3 / 2$ in the weakest magnetic field) of the copper(II) complex $\mathrm{Cu}^{2+}(\mathrm{C})$ measured at $153-213 \mathrm{~K}$ shows a superhyperfine structure (shfs) with line intensities 1:2:3:2:1, which is better seen with decreasing temperature. This shfs shown in Fig. 6 is originating from interaction of the copper ${ }^{63} \mathrm{Cu}(I=3 / 2)$ or ${ }^{65} \mathrm{Cu}(I=3 / 2)$ nucleus with two ${ }^{14} \mathrm{~N}(I=1)$ nuclei of two ammonia, $\mathrm{NH}_{3}$, ligand molecules, forming the $\mathrm{H}_{3} \mathrm{~N}-\mathrm{Cu}^{2+}-\mathrm{NH}_{3}$ complex $[6,9]$ according to the following reaction:

$$
\mathrm{H}_{4} \mathrm{~N}^{+}+\mathrm{Cu}^{2+}+{ }^{+} \mathrm{NH}_{4} \rightarrow \mathrm{H}_{3} \mathrm{~N}-\mathrm{Cu}^{2+}-\mathrm{NH}_{3}+2 \mathrm{H}^{+} .
$$

This model explains that the copper $\mathrm{Cu}^{2+}$ cations are occupying an interstitial position between two $\mathrm{NH}_{4}^{+}$cations (probably at $\mathrm{NH}_{4}^{+}(1 / 4)$ and $\mathrm{NH}_{4}^{+}(3 / 4)$ positions) transformed by deprotonation into $\mathrm{NH}_{3}$ molecules. The central $\mathrm{Cu}^{2+}$ cation is coordinated by two ammonia, $\mathrm{NH}_{3}$, ligand molecules and by three monodentate nitrate $\mathrm{NO}_{3}^{-}$anions, forming a pentacoordinated trigonal bipiramide $\left(D_{3 h}\right)$ mentioned above. 

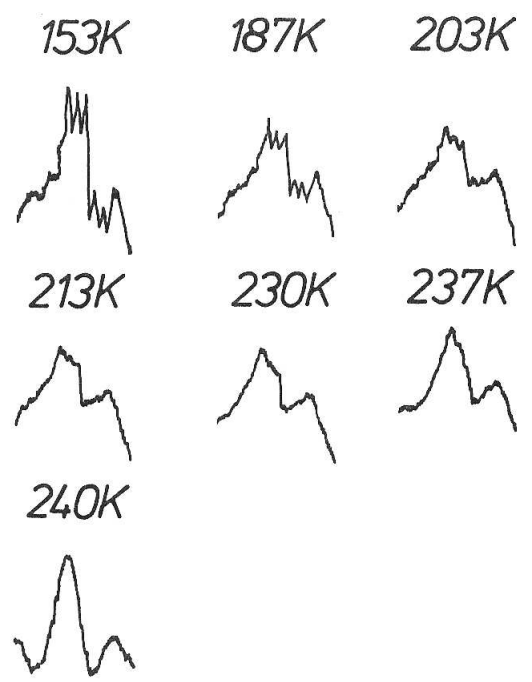

Fig. 6. Temperature dependence of the lineshape for the first hfs line of the $\mathrm{Cu}^{2+}(\mathrm{C})$ complex showing the evolution of the superhyperfine structure.

The individual shfs lines were found to be Gaussian in shape. The nitrogen hyperfine splitting factor $A_{\mathrm{N}}$ and the individual linewidth $\Delta B_{\mathrm{pp}}$ of the shfs line are nearly equal and amount to $A_{\mathrm{N}} \approx \Delta \mathrm{B}_{\mathrm{pp}} \approx 0.77 \mathrm{mT}$.

\section{References}

[1] C.S. Choi, J.E. Mapes, E. Prince, Acta Crystallogr. B 28, 1357 (1972).

[2] M. Ahtee, K.J. Smolander, B.W. Lucas, A.W. Hewat, Acta Crystallogr. C 39, 651 (1983).

[3] W. Wojtowicz, A.B. Więckowski, in: XX International Seminar on Radio- and Microwave Spectroscopy RAMIS'03 in Inhomogeneous Systems, April, Poznań 2003, Abstracts, P-14.

[4] F.J. Owens, J. Appl. Phys. 53, 368 (1982).

[5] U. Tumkurkar, A. Anand, H.L. Bhat, S.V. Bhat, in: Modern Applications of EPR/ESR: From Biophysics to Materials Science, Proc. the First Asia-Pacific EPR/ESR Symposium, January, Hong Kong 1997, Ed. Cz.Z. Rudowicz, Springer-Verlag, Singapore 1998, p. 453.

[6] S.K. Hoffmann, Acta Phys. Pol. A 49, 253 (1976).

[7] C.S. Choi, H.J. Prask, E. Prince, J. Appl. Crystallogr. 13, 403 (1980).

[8] Ya.Ya. Abolin'sh, S.V. Karpov, A.A. Shultin, Sov. Phys., Solid State 20, 3660 (1978).

[9] E. Di Mauro, W. Sano, J. Phys., Condens. Matter 6, L81 (1994). 